\title{
Heritability of problem drinking and the genetic overlap with personality in a general population sample
}

\section{Marleen H. M. de Moor ${ }^{1,2}$, Jacqueline M. Vink ${ }^{1,3}$, Jenny H. D. A. van Beek ${ }^{1,2}$, Lot M. Geels ${ }^{1,2}$, Meike Bartels ${ }^{1,2,3}$, Eco J. C. de Geus ${ }^{1,2,3}$, Gonneke Willemsen ${ }^{1,2,3}$ and Dorret I. Boomsma ${ }^{1,2,3}$}

\author{
' Department of Biological Psychology, VU University Amsterdam, Amsterdam, Netherlands \\ ${ }^{2}$ EMGO+ Institute for Health and Care Research, VU University Medical Center Amsterdam, Amsterdam, Netherlands \\ ${ }^{3}$ Neuroscience Campus Amsterdam, VU University Medical Center Amsterdam, Amsterdam, Netherlands
}

\section{Edited by:}

Maria Grigoroiu-Serbanescu,

Alexandru Obregia Clinical Psychiatric

Hospital, Medical University

Bucharest, Romania

Reviewed by:

Andrew Littlefield, University of

Missouri, USA

Robert C. Elston, Case Western

Reserve University, USA

*Correspondence:

Marleen H. M. de Moor, Department of Biological Psychology, VU

University Amsterdam, van der

Boechorststraat 1, 1081 BT

Amsterdam, Netherlands.

e-mail:m.h.m.de.moor@vu.nl
This study examined the heritability of problem drinking and investigated the phenotypic and genetic relationships between problem drinking and personality. In a sample of 5,870 twins and siblings and 4,420 additional family members from the Netherlands Twin Register. Data on problem drinking (assessed with the AUDIT and CAGE; 12 items) and personality [NEO Five-Factor Inventory (FFI); 60 items] were collected in 2009/2010 by surveys. Confirmatory factor analysis on the AUDIT and CAGE items showed that the items clustered on two separate but highly correlated $(r=0.74)$ underlying factors. A higher-order factor was extracted that reflected those aspects of problem drinking that are common to the AUDIT and CAGE, which showed a heritability of $40 \%$. The correlations between problem drinking and the five dimensions of personality were small but significant, ranging from 0.06 for Extraversion to -0.12 for Conscientiousness. All personality dimensions (with broad-sense heritabilities between 32 and $55 \%$, and some evidence for non-additive genetic influences) were genetically correlated with problem drinking. The genetic correlations were small to modest (between $|0.12|$ and $|0.41|)$. Future studies with longitudinal data and DNA polymorphisms are needed to determine the biological mechanisms that underlie the genetic link between problem drinking and personality.

Keywords: problem drinking, personality, five-factor model, factor analysis, heritability, genetic correlation, twins

\section{INTRODUCTION}

Alcohol use disorders (i.e., alcohol dependence and alcohol abuse) are among the most common mental health problems in Western societies. Across European countries, the 12-month prevalences of alcohol dependence are estimated to range from 0.4 to $14.5 \%$ in men and from 0.1 to $4.2 \%$ in women; for alcohol abuse/harmful use these rates are $1.3-18.5 \%$ in men and $0.2-3.7 \%$ in women. Lifetime prevalences are even higher, with upper limits of $15-20 \%$ in men and around 5\% in women (Rehm et al., 2005). Similar rates have been found in the USA, with the highest prevalence found for lifetime alcohol dependence in men $(20.1 \%)$ and the lowest for 12-month alcohol abuse in women (1.6\%; Kessler et al., 1994, 2005). Alcohol abuse and dependence have harmful consequences for the health and psychological well-being of an affected individual and for his or her social environment (Rehm et al., 2009, 2010; Nutt et al., 2010). Moreover, there is a high comorbidity between alcohol use disorders with externalizing disorders such as attention deficit hyperactivity disorder (ADHD) and Borderline personality disorder, but also with internalizing disorders such as anxiety and depression (Kendler et al., 2011a; Swendsen et al., 2010). Because of these harmful consequences and comorbidity, it is important to increase the understanding of their etiology.

Genetic factors play an important role in explaining the development of alcohol use disorders (Dick et al., 2009). The heritability of alcohol dependence is estimated to range between 40 and 65\%, with no evidence for quantitative or qualitative sex differences in heritability (Kendler et al., 1994; Heath et al., 1997; Prescott and Kendler, 1999; Hansell et al., 2008). Similar heritability estimates have been found for alcohol phenotypes that predict alcohol use disorders, such as weekly number of drinks, quantity times frequency of consumption, timing of first alcohol use, heavy drinking, and symptoms of problem drinking (Heath et al., 1991; Whitfield et al., 2004; Hansell et al., 2008; Grant et al., 2009; Sartor et al., 2009; van Beek et al., 2011). A recent genome-wide association (GWA) study found evidence for genetic variants influencing alcohol consumption (Schumann et al., 2011). Moreover, multivariate twin studies have consistently shown that there is substantial overlap in the genetic factors influencing alcohol dependence and different aspects of consumption, with genetic correlations that range between 0.59 and 0.97 (Whitfield et al., 2004; Grant et al., 2009; Sartor et al., 2009).

Two widely used self-report measures of problem drinking are the AUDIT and the CAGE (Ewing, 1984; Saunders et al., 1993). Self-report measures of problem drinking provide a good alternative to diagnosis-based measures of alcohol use disorders in large (genetic) epidemiological studies, because it is less costly and time consuming to collect self-report data. The AUDIT was originally developed as a screening instrument for hazardous and harmful alcohol consumption. It assesses the amount of alcohol consumption, and the occurrence of alcohol dependence symptoms and alcohol-related problems in the last 12 months (Saunders et al., 1993). The CAGE has been developed as a screening instrument 
to detect alcoholism and asks about ever having had problems with cutting down drinking, being annoyed by criticism on drinking, feeling guilty about drinking, and having a drink in the morning (Ewing, 1984). The AUDIT and CAGE have modest to good specificity and sensitivity (generally ranging between 0.7 and 1 ) to detect alcohol dependence or abuse in a variety of settings and populations (Bradley et al., 1998; Dhalla and Kopec, 2007; Reinert and Allen, 2007; Boschloo et al., 2010). Few studies have included both measures of problem drinking, and it is currently unclear to what extent they measure the same underlying construct.

The genetic influences on alcohol use problems are thought to be partly mediated by individual differences in personality. Externalizing personality traits such as novelty seeking, disinhibition, low conscientiousness, low agreeableness, and antisocial personality are phenotypically related to alcohol abuse and dependence (Lynam et al., 2003; Sher et al., 2005; Krueger et al., 2007; Ruiz et al., 2008). Significant associations have also been observed between neuroticism and symptoms of anxiety and depression with alcohol phenotypes, although these associations are typically less strong than the associations with externalizing traits (Graham et al., 2007; Ruiz et al., 2008). These studies have examined different personality scales but nevertheless converge on the same findings. A recent meta-analysis into the relationship between the five-factor model (FFM) of personality and externalizing pathology including substance use disorders found that alcohol abuse and dependence are characterized by moderately low levels of Agreeableness $(r=-0.20)$ and Conscientiousness $(r=-0.32)$ and moderately high levels of Neuroticism ( $r=0.26$; Ruiz et al., 2008).

There is one study that previously investigated the genetic relationship between alcohol use problems and the FFM of personality (Littlefield et al., 2011). In this study of 2,094 young adult female twins (18-29 years) who reported drinking at least six instances, the genetic overlap between four personality traits (Constraint, measured with the Multidimensional Personality Questionnaire and Neuroticism, Agreeableness and Conscientiousness, measured with the NEO Personality Inventory), drinking motives and alcohol use disorder symptoms was assessed. Phenotypic correlations between the personality traits and alcohol use disorder symptoms were 0.13 for Neuroticism and ranged between -0.16 and -0.20 for the three other traits. Genetic correlations were moderate $(0.33$ for Neuroticism, -0.45 for Agreeableness, -0.40 for Conscientiousness, and -0.50 for Constraint) and were partly mediated by genetic influences on drinking to cope. We aim to replicate findings on the phenotypic and genetic relationships between personality traits and alcohol problems, and extend previous studies by including male twins and non-twin siblings of a wider age range.

The main aims of our study are (1) to establish the factor structure of two self-report measures of problem drinking, (2) to assess the heritability of problem drinking, (3) to determine the associations between problem drinking and the five FFM personality scales, and (4) to compute the genetic overlap between problem drinking and the FFM personality scales. To this end, data were analyzed on two indices of problem drinking (AUDIT and CAGE; 12 items) and the FFM of personality collected (NEO-FFI; 60 items) in a survey sent out in 2009/2010 to all adult participants in the Netherlands Twin Register (NTR). The total sample size available for the factor analysis was 10,290 from 4,891 families. Data from 4,624 twins and 1,246 siblings were used for the genetic analyses.

\section{MATERIALS AND METHODS PARTICIPANTS}

Data for this study came from participants who are voluntarily registered with the NTR. The NTR longitudinally follows adolescent and adult twins and their relatives (parents, siblings, spouses, and adult offspring; Boomsma et al., 2006). The 8th survey, sent out in 2009/2010, contained a large number of questions about lifestyle, health, and personality. We analyzed the 2009/2010 survey data on problem drinking and personality. At the time of data analysis, there were data from 13,117 individuals, of whom 7,123 (54.3\%) completed the questionnaire online. All participants aged 18 or older who ever drank alcohol were selected $(12,429)$, based on the rationale that individuals who never drank alcohol cannot have developed any alcohol problems. We retained individuals who ever drank alcohol but were at the time of assessment not drinking, because the CAGE measure of alcohol problems asks about ever having had alcohol problems. It should be noted however that the number of participants who ever drank alcohol but were not drinking at the time of assessment was small $(0.5 \%$ of the sample), and thus exclusion of this small group is expected to have a negligible impact on our results. Participants with invalid or missing data on personality or problem drinking were excluded, as well as twins with unknown zygosity and triplets. This resulted in a final sample of 10,290 participants (6,291 women), of whom there were 4,624 twins, 1,246 siblings, 3,644 parents, 573 spouses, and 203 adult offspring of twins and siblings. The mean age (SD) of the participants was 41.8 (15.4) years old (age ranged from 18 to 89 ). Data from this sample were the basis for the factor analyses. For the genetic analyses, we selected the data from twins and their siblings [66\% women, mean age (SD) 33.4 (13.0)]. There were 671 monozygotic male (MZM), 401 dizygotic male (DZM), 1,626 monozygotic female (MZF), 854 dizygotic female (DZF) twins, and 1,072 dizygotic twins of opposite-sex (DOS) with valid data on FFM personality and problem drinking (1,263 complete twin pairs). There were 491 brothers and 755 sisters of twins. Zygosity of same-sex twins was determined by DNA typing or was based on six items on physical similarity and the frequency of confusion of the twins by parents, other family members, and strangers.

\section{MEASURES}

Problem drinking was assessed with two self-report scales: the AUDIT and the CAGE (Ewing, 1984; Saunders et al., 1993). The AUDIT consists of 10 questions that assess the three domains: alcohol consumption, alcohol dependence symptoms, and alcoholrelated problems. The CAGE contains four items about cutting down drinking, being annoyed by criticism on drinking, feeling guilty about drinking, and having a drink in the morning. The AUDIT asks to report on problem drinking in the last 12 months, while the CAGE asks about ever having had problems with drinking. Two items are highly similar in content: item 7 from the AUDIT overlaps with item 3 of the CAGE (feeling guilty about drinking) and item 10 from the AUDIT overlaps with item 2 of the CAGE (other people criticized or been concerned about drinking). 
Therefore these items were included only once in the survey, with the answering categories "no," "yes, but not the last 12 months," and "yes, in the last 12 months." Hence, these items could be scored either as required for the AUDIT or for the CAGE. The other AUDIT items (except item 2 about number of drinks on a typical day) had five answer categories. Following the scoring proposed by Saunders et al. (1993), all AUDIT items could be assigned a score of $0-4$. For descriptive purposes, sum scores were computed for AUDIT (ranging from 0 to 40) and CAGE (ranging from 0 to 4). Saunders et al. (1993) suggested a cut-off of 8 or higher on the AUDIT score to indicate the possible presence of an alcohol use disorder. For the CAGE, a score of 2 or higher has been suggested as indicative of alcoholism (Ewing, 1984). For the factor analyses in this paper, we analyzed the 12 items rather than the sum scores: 8 items from the AUDIT, 2 from the CAGE, and the 2 overlapping items. The overlapping items were scored according to the CAGE and the AUDIT and enabled us to investigate whether the factor structure depended on the scoring.

Personality was assessed with the NEO Five-Factor Inventory (NEO-FFI; 60 item short-form of the NEO; Costa and McCrae, 1992; Hoekstra et al., 1996). The NEO-FFI taps the five personality traits Neuroticism, Extraversion, Openness to Experience, Agreeableness, and Conscientiousness and contains 60 items (12 items per trait). Items were answered on a 5-point Likert-type scale ranging from strongly disagree (coded 1) to strongly agree (coded 5). Summed scores were computed for all five personality traits (after reversing negatively keyed items). If 10 or more items were missing, the summed scores for each trait were not computed. If less than 10 items were missing, missing data were imputed with the neutral option (replacing the missing value by a code 3 ), as described in the Dutch manual (Hoekstra et al., 1996). The Cronbach's alpha's for Neuroticism, Extraversion, Openness to Experience, Agreeableness, and Conscientiousness were, respectively, 0.86, 0.78, 0.69, 0.73 , and 0.71 .

\section{STATISTICAL ANALYSES}

Firstly, a confirmatory factor analysis (CFA) was conducted to determine the factor structure of the AUDIT and CAGE items. Two competing models were tested: a one-factor model which tested whether all items from both the AUDIT and CAGE could be summarized with one underlying problem drinking factor. The second model was a two-factor model in which all four CAGE items (including the two items that overlap with AUDIT) loaded on the first factor and the eight remaining items from the AUDIT on the second factor. In this model, the two factors were allowed to correlate. From the best model based on CFA, the factor scores were saved, and used in the genetic analyses. The advantage of using the factor scores is that they use the best information of all problem drinking items with removal of measurement error. The factor scores are therefore thought to represent a more reliable measure of problem drinking than the sum scores of the AUDIT or CAGE. CFA was conducted in Mplus, version 5 (Muthén and Muthén, 2007). ProMAX rotation was applied, which allows the factors to be correlated. The root mean squared error approximation (RMSEA; Steiger, 1990) was used as a fit index to determine with how many factors the items are most parsimoniously described. An RMSEA value smaller than 0.05 is generally accepted as indicating good fit and an RMSEA value between 0.05 and 0.08 as adequate fit (Schermelleh-Engel and Moosbrugger, 2003). RMSEA has also been shown to perform well in the context of categorical data (Yu, 2002). The option TYPE = COMPLEX accounted for the dependencies among observations due to familial clustering. This option has been shown to correct the bias in SEs and fit statistics when analyzing family data (Rebollo et al., 2006).

Secondly, univariate genetic analyses of the problem drinking factor scores obtained in twins and siblings were conducted, to establish the heritability of problem drinking. All genetic analyses were conducted in Mx using maximum likelihood based structural equation modeling (Neale and Cardon, 1992; Neale et al., 2006). An assumption of the twin design is that environmentally caused similarity is approximately the same in MZ and DZ twins (equal environment assumption; (Plomin et al., 2001). It was investigated whether twin-sibling differences should be taken into account in the genetic analyses. For the problem drinking factor score, there were no significant twin-sibling differences in means ( $\left.\chi_{\mathrm{df}=2}^{2}=1.02, p=0.60\right)$ or variances $\left(\chi_{\mathrm{df}=2}^{2}=2.05, p=0.36\right)$ in neither males or females. Further, DZ twin-twin correlations could be equated to correlations in twin-sibling and sibling-sibling pairs in all three groups of male-male, female-female, and opposite-sex pairs $\left(\chi_{\mathrm{df}=3}^{2}=3.78, p=0.29\right)$. Thus, in the full univariate saturated model, 2 means (one for each sex), 2 variances (one for each sex), and 5 twin/sibling correlations (one for each zygosity by sex group) of the problem drinking factor score were estimated. In this model, sex differences in means, variances, and twin/sibling correlations were tested. In a genetic model, the variance of problem drinking was decomposed into genetic and environmental components. Depending on the correlation pattern observed for MZ and DZ twin/sibling pairs, we either fitted an ACE model in which we estimated the additive genetic $(A)$ variance, shared environmental $(C)$ variance, and unique environmental $(E)$ variance, or we fitted an ADE model in which we estimated the non-additive genetic $(D)$ variance rather than the shared environmental variance. MZ twin pairs share (nearly) all of their genetic material, and therefore the correlation between both additive genetic and non-additive genetic factors is 1 in those pairs. In contrast, the additive genetic correlation in DZ twin and sibling pairs is 0.5 and the non-additive genetic correlation 0.25 (Falconer and Mackay, 1996). Both MZ and DZ/sibling pairs by definition share all of their shared environmental factors. Therefore, if the DZ and sibling correlations were more than half of the magnitude of the MZ correlations, an ACE model was fitted. If the DZ and sibling correlations were lower than half of the $\mathrm{MZ}$ correlations, an $\mathrm{ADE}$ model was run. If significant sex differences in phenotypic variances were observed, a genetic scalar model was fitted to the data, in which heritabilities $\left(h^{2}\right)$ were constrained to be equal across sexes. In the genetic scalar model, the variance components for females are constrained to be equal to a scalar multiple $(s)$ of the male variance components, such that $A_{\mathrm{f}}=s^{*} A_{\mathrm{m}}, C_{\mathrm{f}}=s^{*} C_{\mathrm{m}}$ (or $\left.D_{\mathrm{f}}=s^{*} D_{\mathrm{m}}\right)$, and $E_{\mathrm{f}}=s^{*} E_{\mathrm{m}}$. As a result, the standardized variance components (such as heritabilities) are equal across sexes, while the unstandardized components may differ (Boomsma et al., 1996; Distel et al., 2009).

Thirdly, a series of bivariate analyses of twin and sibling data were performed to test whether problem drinking is correlated 
with the personality traits from the FFM of personality. A previous study showed that there are no significant twin-sibling differences in means, variances, or correlations for the five personality traits (Distel et al., 2009). Several studies have also tested the equal environment assumption for personality and showed that there is no evidence that the assumption is violated (e.g., Borkenau et al., 2002). In each bivariate saturated model, the following correlations were estimated: the cross-trait within-twin/sib correlation (i.e., the phenotypic correlation among traits) in men and women ( 2 correlations), the within-trait twin/sib correlations for each zygosity by sex group for problem drinking and the specific personality trait $(5 \times 2=10$ correlations $)$ and the cross-trait cross-twin/sib correlations for each zygosity by sex group ( 5 correlations). In addition to the correlations, 4 means, 4 variances, and 4 regression effects of age on the means (for both traits in men and women) were obtained, resulting in a total of 29 estimated parameters in the bivariate model. Sex differences in means, variances, and twin/sibling correlations were evaluated.

The cross-trait covariance structure formed the basis to decompose the association of problem drinking and each personality trait into a genetic and environmental part in a bivariate model (Neale and Cardon, 1992). We tested for each trait and for the covariance among traits, whether the $A$ and $C$ or $D$ components could be dropped from the model without a significant deterioration of model fit. Model fit was evaluated with the log-likelihood ratio test by comparing the log-likelihood of the nested sub model with the full model, which is chi-square distributed with the degrees of freedom equal to the difference in number of free parameters between the two models. The alpha level used in the genetic analyses was 0.01 .

\section{RESULTS \\ DESCRIPTIVES FOR PROBLEM DRINKING}

The distributions of sum scores on the AUDIT and the CAGE and their associations with sex and age are provided in Table 1. A little more than $10 \%$ of the participants score above the suggested threshold for a possible alcohol use disorder on both the
AUDIT and the CAGE. Of the participants scoring above the suggested threshold on the AUDIT, 53\% also scores above the suggested threshold for the CAGE (for those above the CAGE threshold, $56 \%$ is also above the AUDIT threshold). The correlation between the AUDIT and CAGE sum scores is 0.62. Men score higher than women and more often score above the clinical thresholds $\left(\chi_{\mathrm{df}=1}^{2}=246.3, p<0.001\right.$ for AUDIT and $\chi_{\mathrm{df}=1}^{2}=93.7$, $p<0.001$ for CAGE). The regression of AUDIT on age shows both significant linear and quadratic terms in both men and women, indicating that younger adults (18-40 years) show more problem drinking than middle aged adults (40-60), and older adults (6090) show increased problem drinking again. A linear or quadratic effect with age is not seen for the CAGE.

\section{FACTOR ANALYSES FOR PROBLEM DRINKING ITEMS}

The one-factor model did not fit the data well (RMSEA $=0.087$ ), but the two-factor model separating CAGE and AUDIT provided adequate fit $(\mathrm{RMSEA}=0.063)$ and was thus kept as the best fitting model. The standardized factor loadings of this model ranged from 0.44 to 0.90 for factor 1 , and from 0.42 to 0.98 for factor 2 . The two factors were highly correlated $(r=0.74)$. These results show that the items of the AUDIT and CAGE to a large extent but not fully represent one underlying problem drinking construct. The correlation between the AUDIT sum score with the AUDIT factor score was 0.86 , and that between the CAGE sum score and the CAGE factor score was 0.90. The correlation between the AUDIT sum score with the CAGE factor score was 0.76, and between the CAGE sum score with the AUDIT factor score it was 0.61 . This pattern of correlations suggests that the AUDIT and CAGE items tap two highly related dimensions of the problem drinking construct. Hence, a second-order two-factor model was fitted in which the correlation among the two factors is explained by one higher-order factor (see Figure 1). This model is identified by constraining the two factor loadings to be equal, and this constraint makes the secondorder model equivalent in terms of number of parameters, fit and estimates to the two-factor model without the second-order factor. The second-order model enables us to save the factor scores of

Table 1 | Distributions of AUDIT and CAGE and their associations with sex and age.

\begin{tabular}{|c|c|c|c|c|c|}
\hline & Range & Mean (SD) & $\begin{array}{l}\% \text { Above clinical } \\
\text { cut-off }^{\mathrm{a}}\end{array}$ & $\begin{array}{l}\text { Linear relation } \\
\text { with }^{\text {age }}{ }^{b}\end{array}$ & $\begin{array}{l}\text { Quadratic relation } \\
\text { with age }^{\text {b }}\end{array}$ \\
\hline \multicolumn{6}{|l|}{ AUDIT } \\
\hline Total sample & $0-40$ & 4.21 (3.65) & 13.0 & $-0.05^{* *}$ & $0.09 * *$ \\
\hline Men & $0-34$ & $5.22(4.09)$ & 19.5 & $-0.12 * *$ & $0.07^{* *}$ \\
\hline Women & $0-40$ & 3.57 (3.18) & 8.9 & $-0.03^{*}$ & $0.10^{* *}$ \\
\hline \multicolumn{6}{|l|}{ CAGE } \\
\hline Total sample & $0-4$ & $0.44(0.82)$ & 12.3 & 0.02 & -0.01 \\
\hline Men & $0-4$ & $0.59(0.92)$ & 16.3 & -0.03 & -0.02 \\
\hline Women & $0-4$ & $0.35(0.73)$ & 9.8 & 0.03 & -0.02 \\
\hline
\end{tabular}

${ }^{a}$ Clinical cut-off for AUDIT is sum score of 8 or higher (Saunders et al., 1993), for CAGE sum score of 2 or higher (Ewing, 1984).

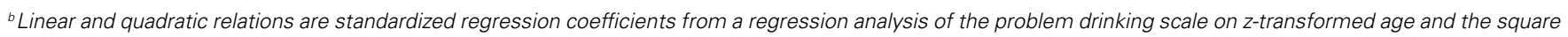
of z-transformed age.

${ }^{*} p<0.01$.

${ }^{* *} p<0.001$. 
the higher-order factor, which is thought to reflect those aspects of problem drinking that are common to the AUDIT and CAGE (correlations of this higher-order factor score with AUDIT and CAGE sum scores were, respectively 0.84 and 0.77 ). The higher-order factor scores were used in subsequent genetic analyses.

\section{TWIN-SIBLING ANALYSES OF PROBLEM DRINKING AND THE FFM PERSONALITY SCALES}

In the univariate saturated model for problem drinking, and in the five bivariate saturated models we estimated the mean and covariance structure for problem drinking and each of the five personality scales in twins and siblings. Men scored higher on problem

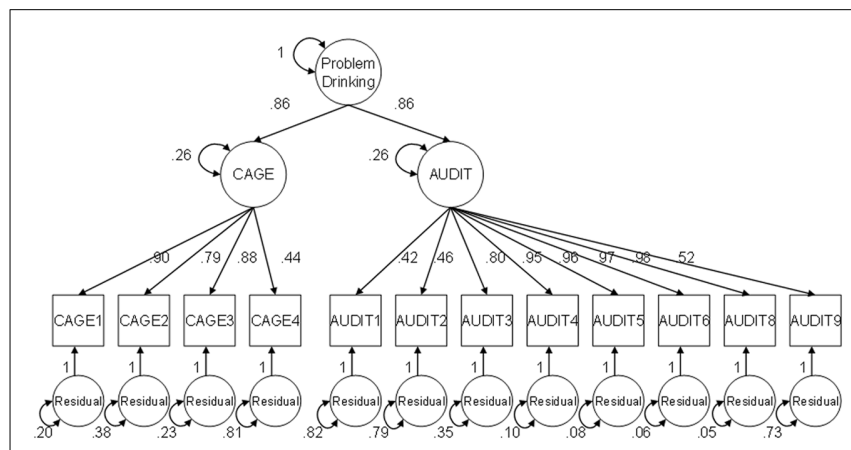

FIGURE 1 | Higher-order two-factor model for the items of two problem drinking scales, the AUDIT and CAGE. Note: single-headed arrows represent standardized factor loadings, double-headed arrows represent total variance for the Problem drinking factor and residual variances for all other factors depicted in the figure. Factor loadings of 1 are fixed parameters, the factor loadings of problem drinking on CAGE and AUDIT are constrained to be equal; these constraints ensure that the factor model is identified. drinking than women $(p<0.001)$, whereas women scored higher on Neuroticism and Agreeableness $(p<0.001$; see Table 2 for estimates). There were no significant sex differences in means for Extraversion, Openness to Experience, and Conscientiousness. The variances of problem drinking in men and women were not significantly different ( $p=0.11$; Table 2 ), but there were significant differences in variances across sex for Neuroticism, Openness to Experience, and Conscientiousness $(p<0.001)$, with a larger variance for Neuroticism in women, and larger variances for Openness to Experience and Conscientiousness in men. There were no significant sex differences in the phenotypic correlations $(p>0.01$; Table 2). The phenotypic correlations were relatively low but all significant (ranging between $10.06 \mid$ and $10.12 \mathrm{I}$ ). Agreeableness $(-0.09)$ and Conscientiousness $(-0.12)$ were most strongly (and negatively) associated with problem drinking: low scores on Agreeableness and Conscientiousness were related to more problem drinking. Somewhat lower correlations were seen for the other personality traits, where those who scored highest on Neuroticism, Extraversion, and Openness to Experience scored highest on problem drinking.

The within-trait cross-twin/sibling correlations for problem drinking and each of the five personality scales are given in the upper part of Table 3. Sex differences in these twin/sibling correlations were not significant $(p>0.01)$. When constrained over sexes, the MZ correlation for problem drinking (0.39) is about twice as large as the DZ correlation (0.21), suggesting the presence of additive genetic influences and the absence of non-additive genetic and shared environmental influences for problem drinking. The MZ correlations for the five FFM personality scales range between 0.36 and 0.58 ; the $\mathrm{DZ}$ correlations range between 0.11 and 0.22 . For all five personality traits, the $\mathrm{MZ}$ correlation is larger than twice the DZ correlation, suggesting that both additive

Table 2 | Means, variances, and phenotypic correlations for problem drinking and the FFM personality scales as obtained from the saturated models.

\begin{tabular}{|c|c|c|c|c|c|}
\hline & \multicolumn{2}{|c|}{ Means } & & \multicolumn{2}{|c|}{ Variances } \\
\hline & Men & Women & & Men & Women \\
\hline Problem drinking & 0.51 & $0.14^{*}$ & & 0.43 & 0.40 \\
\hline Neuroticism & 28.3 & $33.6^{*}$ & & 49.9 & $56.0^{*}$ \\
\hline Extraversion & 45.8 & 44.9 & & 35.0 & 33.1 \\
\hline Openness to experience & 36.0 & 36.6 & & 36.0 & $30.7^{*}$ \\
\hline Agreeableness & 41.6 & $43.9 *$ & & 23.3 & 21.8 \\
\hline \multirow[t]{3}{*}{ Conscientiousness } & 43.2 & 44.2 & & 33.3 & $27.8^{*}$ \\
\hline & \multicolumn{3}{|c|}{ Phenotypic correlations } & & \\
\hline & Men & Women & All & & \\
\hline Problem drinking - neuroticism & 0.08 & 0.09 & 0.09 & & \\
\hline Problem drinking - extraversion & 0.04 & 0.07 & 0.06 & & \\
\hline Problem drinking - openness to experience & 0.03 & 0.09 & 0.07 & & \\
\hline Problem drinking - agreeableness & -0.10 & -0.09 & -0.09 & & \\
\hline Problem drinking - conscientiousness & -0.11 & -0.13 & -0.12 & & \\
\hline
\end{tabular}

All reported statistics are corrected for age. ${ }^{*} p<0.001$ for the test of sex differences. 
and non-additive influences play a role in explaining variation in personality. Shared environmental influences do not seem to explain variation in personality.

The lower part of Table 3 shows the cross-trait crosstwin/sibling correlations for problem drinking and the FFM personality scales. Again, sex differences in these correlations were not significant $(p>0.05)$. The MZ cross correlations are larger than the DZ correlations, except for Agreeableness with problem drinking, where the $M Z$ and DZ correlation estimates are similar. This general pattern of $M Z$ and DZ cross correlation suggests that the small but significant correlations between problem drinking and the FFM personality scales can be explained by overlapping genetic factors.

The estimates of the proportions of variance due to $A, D$, and $E$ for each phenotype are given in the upper part of Table 4 . The univariate genetic model for problem drinking showed that the heritability of problem drinking was $40.0 \%$. Consistent with the twin correlations, shared environmental, and non-additive genetic influences were not significant for problem drinking $(p>0.05)$. Based on the results from the bivariate saturated models and consistent with the results from an earlier study on the FFM of personality (Distel et al., 2009), we next fitted bivariate ADE models

Table 3 | Twin/sibling correlations for problem drinking and the FFM personality scales as obtained from the saturated models.

\begin{tabular}{|c|c|c|c|c|c|c|c|}
\hline & MZM & DZM/sibMM & MZF & DZF/sibFF & Dos/sibOS & MZ & $\mathbf{D Z}$ \\
\hline \multicolumn{8}{|c|}{ WITHIN-TRAIT CROSS-TWIN/SIBLING CORRELATIONS } \\
\hline Problem drinking & 0.41 & 0.14 & 0.39 & 0.25 & 0.20 & 0.39 & 0.21 \\
\hline Neuroticism & 0.49 & 0.10 & 0.48 & 0.13 & 0.15 & 0.48 & 0.14 \\
\hline Extraversion & 0.51 & 0.01 & 0.53 & 0.16 & 0.19 & 0.52 & 0.15 \\
\hline Openness to experience & 0.59 & 0.28 & 0.57 & 0.22 & 0.19 & 0.58 & 0.22 \\
\hline Agreeableness & 0.44 & 0.14 & 0.32 & 0.15 & 0.06 & 0.36 & 0.11 \\
\hline Conscientiousness & 0.52 & 0.14 & 0.47 & 0.18 & 0.19 & 0.49 & 0.18 \\
\hline \multicolumn{8}{|c|}{ CROSS-TRAIT CROSS-TWIN/SIBLING CORRELATIONS } \\
\hline Problem drinking - neuroticism & 0.07 & 0.04 & 0.06 & 0.05 & 0.04 & 0.06 & 0.04 \\
\hline Problem drinking - extraversion & -0.01 & -0.01 & 0.08 & 0.01 & 0.001 & 0.06 & 0.002 \\
\hline Problem drinking - openness to experience & 0.04 & 0.02 & 0.10 & 0.05 & 0.02 & 0.08 & 0.03 \\
\hline Problem drinking - agreeableness & -0.04 & -0.00 & -0.03 & -0.03 & -0.03 & -0.03 & -0.03 \\
\hline Problem drinking - conscientiousness & -0.13 & -0.04 & -0.07 & -0.09 & -0.06 & -0.09 & -0.07 \\
\hline
\end{tabular}

MZM, monozygotic male twin pairs; DZM, dizygotic male twin pairs; sibMM, male-male sibling pairs and male twin-male sibling pairs; MZF, monozygotic female twin pairs; DZF, dizygotic female twin pairs; sibFF, female-female sibling pairs and female twin-female sibling pairs; DOS, dizygotic opposite-sex twin pairs; sibOS, dizygotic opposite-sex sibling-sibling and twin-sibling pairs. All reported statistics are corrected for age.

Table 4 | Proportions of variance and the phenotypic correlations explained by genetic and environmental factors and genetic and environmental correlations as obtained from the genetic models for problem drinking and personality.

Proportion of variance explained by

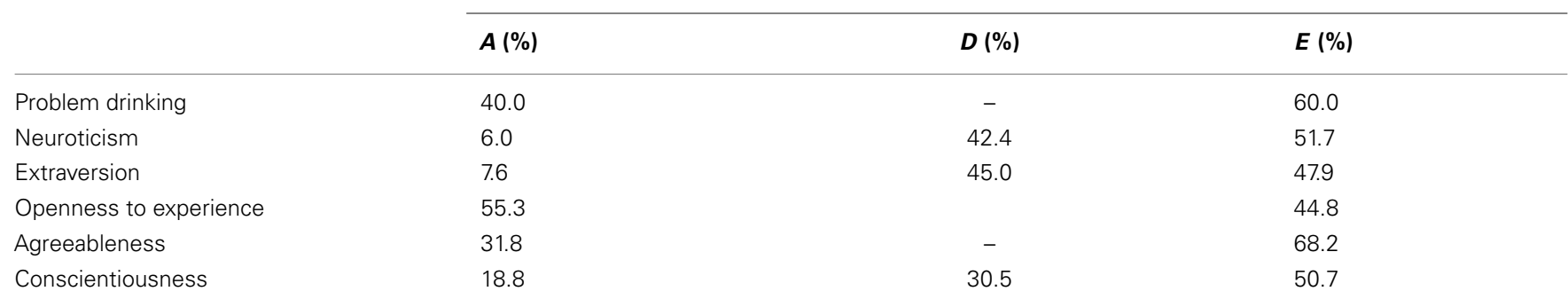

\begin{tabular}{|c|c|c|c|c|}
\hline & \multicolumn{2}{|c|}{ Proportion of the phenotypic correlation explained by } & \multicolumn{2}{|c|}{ Genetic and environmental correlations } \\
\hline & $A(\%)$ & $E(\%)$ & $r_{A}$ & $r_{E}$ \\
\hline Problem drinking-neuroticism & 71.8 & 28.2 & 0.41 & 0.05 \\
\hline Problem drinking-extraversion & 75.9 & 24.1 & 0.26 & 0.03 \\
\hline Problem drinking-openness to experience & 106.9 & -6.9 & 0.17 & -0.01 \\
\hline Problem drinking-agreeableness & 44.8 & 55.2 & -0.12 & -0.08 \\
\hline Problem drinking-conscientiousness & 85.6 & 14.4 & -0.38 & -0.03 \\
\hline
\end{tabular}


to the data. Because the univariate analysis indicated no impact of non-additive genetic influences for problem drinking, these influences were set to zero for problem drinking. As a result, overlapping non-additive genetic influences were also not possible. For Neuroticism, Openness to Experience, and Conscientiousness a scalar was added in female twins and siblings to account for the significant differences in the phenotypic variances across sex. $D$ was significant for Neuroticism $\left(\chi_{\mathrm{df}=1}^{2}=14.5, p=0.001\right)$, Extraversion $\left(\chi_{\mathrm{df}=2}^{2}=16.82, p<0.001\right)$, and Conscientiousness $\left(\chi_{\mathrm{df}=1}^{2}=8.46, p=0.004\right)$, but $D$ was not significant for Openness to Experience and Agreeableness $(p>0.01)$. The broadsense heritabilities of the FFM personality scales ranged between $31.8 \%$ for Agreeableness to $55.3 \%$ for Openness to Experience. The broad-sense heritability for Neuroticism (48.4\%) consists of a proportion of $6.0 \%$ additive genetic variance and $42.4 \%$ non-additive genetic variance. Similar estimates are obtained for Extraversion (broad-sense heritability $52.6 \%$, of which $7.6 \% A$ and $45.0 \% D$ ) and Conscientiousness (broad-sense heritability $49.3 \%$, of which $18.8 \% A$ and $30.5 \% D$ ).

The estimates of the proportions of the phenotypic correlations due to $A$ and $E$ and the additive genetic and unique environmental correlations are provided in the lower part of Table 4. A large part of the correlations between problem drinking and the FFM of personality can be explained by additive genetic influences, with proportions of the phenotypic correlations ranging from 44.8\% for the overlap with Agreeableness and 106.9\% for Openness to Experience. Note that the proportion of the phenotypic correlation explained by additive genetic influences for Openness to Experience is larger than $100 \%$, because the unique environmental correlation is slightly negative $(-0.01)$, thus contributing negatively $(-6.9 \%)$ to the positive phenotypic correlation with problem drinking. Since it is more likely that the small negative environmental correlation results from sampling error in the estimates of the twin correlations rather than from truly environmental factors that have opposite effects on problem drinking and Openness and Experience, we also fitted a model in which the environmental correlation was constrained at zero. In this model, $100 \%$ of the phenotypic correlation is explained by additive genetic influences. The estimate of the genetic correlation is almost the same ( 0.16 instead of 0.17$)$, and the heritability estimates did not change. The genetic correlations vary between -0.12 for Agreeableness and 0.41 for Neuroticism and they are all larger than the observed phenotypic correlations. The relatively large genetic correlations for Neuroticism (0.41), Extraversion (0.26), and Conscientiousness $(-0.38)$ may be the result of the small proportion of $A$ when also modeling $D$. Therefore, we also estimated the genetic correlations in a series of AE models. The genetic correlations for Neuroticism, Extraversion, and Conscientiousness with problem drinking were indeed somewhat lower $(0.16,0.10$, and -0.25 , respectively), but remained significant.

\section{DISCUSSION}

This study reports on the factor structure of the AUDIT and CAGE problem drinking measures in a large population-based sample and examined the heritability of problem drinking and its genetic relationship with personality traits assessed with the NEO. The study was conducted in a sample of 10,290 twins, siblings, and additional family members from the NTR. Factor analysis on the AUDIT and CAGE items showed that the AUDIT and CAGE items clustered on two separate but highly correlated $(r=0.74)$ factors. The scores on the AUDIT and CAGE items were summarized with the second-order factor score into a single problem drinking score, which showed a heritability of $40 \%$. The DZ twin correlation was not different from the twin-sibling or siblingsibling correlation, which suggests that there is no special twin environment and that results from heritability studies on problem drinking in adult twins can be generalized to the non-twin population. Further, we did not find evidence for sex differences in heritability of problem drinking. This is in line with heritability estimates reported in previous twin studies (e.g., Jang et al., 2002; Mustanski et al., 2003; Littlefield et al., 2011), adoption studies (e.g., Cadoret et al., 1986), and non-twin family studies on problem drinking or alcohol use disorders (e.g., Ehlers et al., 2010). The five dimensions of personality were also substantially heritable (between 32 and 55\%), with evidence for non-additive genetic influences for Neuroticism, Extraversion, and Conscientiousness. This is largely consistent with previous twin/sibling studies (e.g., Keller et al., 2005; Distel et al., 2009), adopted twin studies (e.g., Bouchard et al., 1990), and non-twin family studies (e.g., Pilia et al., 2006) on the heritability of personality.

The correlations between the problem drinking factor score and the FFM dimensions of personality were small but significant, ranging from 0.06 for Extraversion to -0.12 for Conscientiousness. The genetic overlap between problem drinking and the personality dimensions varied between -0.12 for Agreeableness to 0.41 for Neuroticism. These results indicate that the genetic factors found for problem drinking partly represent genetic factors for personality, with each of the FFM personality scales contributing a small amount to these genetic factors. The results on the phenotypic and genetic overlap between problem drinking and personality are largely consistent with earlier multivariate twin studies on the relationship between alcohol phenotypes and personality (Jang et al., 2000; Slutske et al., 2002; Mustanski et al., 2003; Kendler et al., 2011b; Littlefield et al., 2011). The effect sizes in our study and those found in Littlefield et al. (2011), both investigating the five domains of the FFM of personality, are somewhat smaller than other studies who use different personality inventories. For example, in the study from Jang et al. (2000) 659 twin pairs were measured on alcohol misuse (four items) and dissocial personality traits assessed with the Dimensional Assessment of Personality Pathology. They report genetic correlations with alcohol misuse that range from 0.10 for lack of empathy to 0.88 for grandiosity. Mustanski et al. (2003) showed in a sample of 1,320 twin pairs that alcohol consumption and related problems were genetically correlated with excitement seeking, measured with two subscales of the Zuckerman's sensation seeking scale, and social deviance assessed with a subscale of the Minnesota Multiphasic Personality Inventory. Genetic correlations ranged between 0.30 and 0.63 and were highest between social deviance and alcohol-related problems and between excitement seeking and alcohol consumption. In the study from Slutske et al. (2002), comprising 6,453 twin pairs, it was shown that a diagnosis of alcohol dependence was significantly genetically correlated with behavioral undercontrol, with positive and negative emotionality in men, and with positive emotionality in women. These three higher-order personality dimensions were based on 
a factor analysis of the Tridimensional Personality Questionnaire and the Eysenck personality Questionnaire. The largest genetic correlations (0.53-0.71) were obtained for behavioral undercontrol. Somewhat lower genetic correlations were found for positive and negative emotionality $(0.06-0.36)$. In the single previous study on alcohol use disorder symptoms and the FFM of personality, conducted in female twin pairs (Littlefield et al., 2011), genetic correlations were found that were highly comparable to those in our study ( 0.33 versus 0.41 for Neuroticism and -0.36 versus -0.40 for Conscientiousness). Only the genetic correlation with Agreeableness was lower in our study $(-0.12)$ compared to that reported in the study by Littlefield et al. (2011) (-0.45). Our study adds to the study of Littlefield et al. (2011) in showing no evidence for twin-sibling or sex differences in the genetic overlap between the FFM of personality and problem drinking. To conclude, we largely corroborate the findings of previous studies by showing that alcohol use (disorders) are genetically correlated with both the internalizing (e.g., high Neuroticism) and externalizing (e.g., low Agreeableness and Conscientiousness) spectra of personality.

The phenotypic and genetic correlations were based on the assumption of a linear relationship between problem drinking and personality. This assumption could be challenged as the relationship between alcohol consumption and personality traits such as neuroticism and depressive symptoms is non-linear (Rodgers et al., 2000; Alati et al., 2005). We examined this by regressing the problem drinking factor scores on each of the personality traits in a model which included linear and quadratic relationships. We found significant linear and quadratic effects for all scales $(p<0.005)$. For example, for Agreeableness and Conscientiousness it was found that the increase in problem drinking becomes stronger with increasingly low levels of Agreeableness and Conscientiousness. This means that individuals who score very high, high, or intermediate on Agreeableness and Conscientiousness do not differ much in problem drinking, but individuals who score low or very low on these personality traits show the highest scores for problem drinking. Similar effects were observed for the other personality traits, where those who score highest on Neuroticism, Extraversion, and Openness to Experience score highest on problem drinking. Thus, the estimated linear correlations reported in this study capture only part of the true strength of the associations between personality and problem drinking. Current genetic models are not able to

\section{REFERENCES}

Alati, R., Lawlor, D. A., Najman, J. M., Williams, G. M., Bor, W., and O'Callaghan, M. (2005). Is there really a "J-shaped" curve in the association between alcohol consumption and symptoms of depression and anxiety? Findings from the Mater-University Study of Pregnancy and its outcomes. Addiction 100, 643-651.

Bierut, L. J., Agrawal, A., Bucholz, K. K., Doheny, K. F., Laurie, C., Pugh, E., Fisher, S., Fox, L., Howells, W., Bertelsen, S., Hinrichs, A. L., Almasy, L., Breslau, N., Culverhouse, R. C.,Dick,

incorporate these non-linear relationships, but may be developed in the future.

Recently, a number of GWA studies came out that attempted to identify the actual genetic variants that underlie personality and alcohol use (disorders; Shifman et al., 2008; van den Oord et al., 2008; Hettema et al., 2009; Bierut et al., 2010; De Moor et al., 2010; Lind et al., 2010; Terracciano et al., 2010; Schumann et al., 2011). Two of these studies yielded genome-wide significant hits, one for personality (De Moor et al., 2010) and one for alcohol consumption (Schumann et al., 2011). The genome-wide significant hits account for a very small portion of the heritabilities of the phenotypes. In the meta-analysis for personality, including more than 17,000 individuals, three genome-wide significant hits were found; two hits for Openness to Experience in an intergenic region on chromosome 5 and one hit for Conscientiousness in the brainexpressed KATNAL2 gene on chromosome 18. In the meta-analysis for alcohol consumption, comprising of 26,316 individuals in the discovery stage and 21,185 individuals in the replication stage, a genome-wide significant hit was found in the AUTS2 gene on chromosome 7. Gene expression analysis in human brains and animal experiments were consistent were the role of this gene to drinking behavior (Schumann et al., 2011). The three genome-wide significant loci for personality were not significantly associated with problem drinking in the Netherlands Twin Registry sample, and the AUTS2 locus was not associated with personality in the large meta-analysis $(p>0.05)$.

To conclude, we showed that in a large general population sample problem drinking is heritable and that there is small to modest genetic overlap between problem drinking and all five dimensions of the FFM of personality. This overlap seems largest for Neuroticism and Conscientiousness. Future studies with longitudinal data and DNA polymorphisms in large collaborative samples are needed to pinpoint to the causal and biological mechanisms that underlie the genetic link between internalizing and externalizing personality and alcohol use (disorders).

\section{ACKNOWLEDGMENTS}

This work was supported by the Netherlands Organization for Scientific Research (NWO; ZonMW Addiction program, grant 31160008). Marleen de Moor is financially supported by NWO VENI grant 016-115-035. Dorret Boomsma is financially supported by the European Research Council (ERC-230374).

Hottenga, J. J., Posthuma, D., Beijsterveldt, T. C. E. M., Hudziak, J. J., Bartels, M., and Willemsen, G. (2006). Netherlands twin register: from twins to twin families. Twin Res. Hum. Genet. 9, 849-857.

Boomsma, D. I., Kempen, H. J. M., Leuven, J. A. G., Havekes, L., deKnijff, P., and Frants, R. R. (1996). Genetic analysis of sex and generation differences in plasma lipid, lipoprotein, and apolipoprotein levels in adolescent twins and their parents. Genet. Epidemiol. 13, 49-60.

Borkenau, P., Riemann, R., Angleitner, A., and Spinath, F. M. (2002).
Similarity of childhood experiences and personality resemblance in monozygotic and dizygotic twins: a test of the equal environments assumption. Pers. Individ. Dif. 33, 261-269.

Boschloo, L., Vogelzangs, N., Smit, J. H., Van den Brink, W., Veltman, D. J., Beekman, A. T. F., and Penninx, B. W. J. H. (2010). The performance of the alcohol use disorder identification test (AUDIT) in detecting alcohol abuse and dependence in a population of depressed or anxious persons. J. Affect. Disord. 126, 441-446. 
Bouchard, T. J., Lykken, D. T., Mcgue, M., Segal, N. L., and Tellegen, A. (1990). Sources of human psychological differences - the Minnesota study of twins reared apart. Science 250, 223-228.

Bradley, K. A., Boyd-Wickizer, J., Powell, S. H., and Burman, M. L. (1998). Alcohol screening questionnaires in women - a critical review. JAMA 280, 166-171.

Cadoret, R. J., Troughton, E., Ogorman, T. W., and Heywood, E. (1986). An adoption study of genetic and environmental-factors in drugabuse. Arch. Gen. Psychiatry 43, 1131-1136.

Costa, P. T., and McCrae, R. R. (1992). Professional Manual: Revised NEO Personality Inventory (NEO-PI-R) and NEO Five-FactorInventory (NEO-FFI). Odessa, FL: Psychological Assessment Resources.

De Moor, M. H. M., Costa, P. T., Terracciano, A., Krueger, R. F., de Geus, E. J. C., Tanaka, T., Penninx, B. W. J. H., Esko, T., Madden, P. A. F., Derringer, J., Amin, N., Willemsen, G., Hottenga, J. J., Distel, M. A., Uda, M., Sanna, S., Spinhoven, P., Hartman, C. A., Sullivan, P., Realo, A., Allik, J., Heath, A. C., Pergadia, M. L., Agrawal, A., Lin, P., Grucza, R. A., Widen, E., Cousminer, D. L., Eriksson, J. G., Palotie, A., Peltonen, L., Luciano, M., Tenesa, A., Davies, G., Houlihan, L. M., Hansell, N. K., Medland, S. E., Ferrucci, L., Schlessinger, D., Montgomery, G. W., Wright, M. J., Aulchenko, Y. S., Janssens, A. C. J. W., Oostra, B. A., Metspalu, A., Abecasis, G. R., Deary, I. J., Raikkonen, K., Bierut, L. J., Martin, N. G., van Duijn, C. M., and Boomsma, D. I. (2010). Metaanalysis of genome-wide association studies for personality. Mol. Psychiatry. PMID: 21173776. [Epub ahead of print].

Dhalla, S., and Kopec, J. A. (2007). The CAGE questionnaire for alcohol misuse: a review of reliability and validity studies. Clin. Invest. Med. 30, 33-41.

Dick, D. M., Prescott, C. A., and Mcgue, M. (2009). "The genetics of substance use and substance use disorders," in The Handbook of Behavior Genetics, ed. Y.K. Kim (New York: Springer), 433-453.

Distel, M. A., Trull, T. J., Willemsen, G., Vink, J. M., Derom, C. A., Lynskey, M. T., Martin, N. G., and Boomsma, D. I. (2009). The five factor model of personality and borderline personality disorder: a genetic analysis of comorbidity. Biol. Psychiatry 66, 1131-1138.
Ehlers, C. L., Gizer, I. R., Vieten, C., Gilder, A., Gilder, D. A., Stouffer, G. M., Lau, P., and Wilhelmsen, K. C. (2010). Age at regular drinking, clinical course, and heritability of alcohol dependence in the San Francisco family study: a gender analysis. Am. J. Addict. 19, 101-110.

Ewing, J. A. (1984). Detecting alcoholism. The CAGE questionnaire. JAMA 252, 1905-1907.

Falconer, D. S., and Mackay, T. F. C. (1996). Introduction to Quantitative Genetics, 4th Edn. Essex: Pearson Education Limited.

Graham, K., Massak, A., Demers, A., and Rehm, J. (2007). Does the association between alcohol consumption and depression depend on how they are measured? Alcohol. Clin. Exp. Res. $31,78-88$.

Grant, J. D., Agrawal, A., Bucholz, K. K., Madden, P. A. F., Pergadia, M. L., Nelson, E. C., Lynskey, M. T., Todd, R. D., Todorov, A. A., Hansell, N. K., Whitfield, J. B., Martin, N. G., and Heath, A. C. (2009). Alcohol consumption indices of genetic risk for alcohol dependence. Biol. Psychiatry 66, 795-800.

Hansell, N. K., Agrawal, A., Whitfield, J. B., Morley, K. I., Zhu, G., Lind, P. A., Pergadia, M. L., Madden, P. A. F., Todd, R. D., Heath, A. C., and Martin, N. G. (2008). Longterm stability and heritability of telephone interview measures of alcohol consumption and dependence. Twin Res. Hum. Genet. 11, 287-305.

Heath, A. C., Bucholz, K. K., Madden, P. A. F., Dinwiddie, S. H., Slutske, W. S., Bierut, L. J., Statham, D. J., Dunne, M. P., Whitfield, J. B., and Martin, N. G. (1997). Genetic and environmental contributions to alcohol dependence risk in a national twin sample: consistency of findings in women and men. Psychol. Med. 27, 1381-1396.

Heath, A. C., Meyer, J., Jardine, R., and Martin, N. G. (1991). The inheritance of alcohol-consumption patterns in a general-population twin sample.2. Determinants of consumption frequency and quantity consumed. J. Stud. Alcohol 52, 425-433.

Hettema, J. M., Van den Oord, E. J. C. G., An, S. S., Kendler, K. S., and Chen, X. N. (2009). Follow-up association study of novel neuroticism gene MAMDC1. Psychiatr. Genet. 19, 213-214.

Hoekstra, H. A., Ormel, J., and De Fruyt, F. (1996). Handleiding NEO Persoonlijkheids-Vragenlijsten NEO$P I-R$ en NEO-FFI. Lisse: Swets Test Services.

Jang, K. L., Livesley, W. J., Angleitner, A., Riemann, R., and Vernon, P. A.
(2002). Genetic and environmental influences on the covariance of facets defining the domains of the fivefactor model of personality. Pers. Individ. Dif. 33, 83-101.

Jang, K. L., Vernon, P. A., and Livesley, W. J. (2000). Personality disorder traits, family environment, and alcohol misuse: a multivariate behavioural genetic analysis. Addiction 95, 873-888.

Keller, M. C., Coventry, W. L., Heath, A. C., and Martin, N. G. (2005). Widespread evidence for non-additive genetic variation in Cloninger's and Eysenck's personality dimensions using a twin plus sibling design. Behav. Genet. 35, 707-721.

Kendler, K. S., Aggen, S. H., Peggy Knudsen, G., Roysamb, E., Neale, M. C., and Reichborn-Kjennerud, T. (2011a). The structure of genetic and environmental risk factors for syndromal and subsyndromal common DSM-IV axis I and all axis II disorders. Am. J. Psychiatry 168, 29-39.

Kendler, K. S., Gardner, C. O., and Prescott, C. A. (2011b). Toward a comprehensive developmental model for alcohol use disorders in men. Twin Res. Hum. Genet. 14 $1-15$.

Kendler, K. S., Neale, M. C., Heath, A. C., Kessler, R. C., and Eaves, L. J. (1994). A twin-family study of alcoholism in women. Am. J. Psychiatry 151, 707-715.

Kessler, R. C., Berglund, P., Demler, O., Jin, R., and Walters, E. E. (2005). Lifetime prevalence and ageof-onset distributions' of DSM-IV disorders in the National Comorbidity Survey replication. Arch. Gen. Psychiatry 62, 593-602.

Kessler, R. C., Mcgonagle, K. A., Zhao, S. Y., Nelson, C. B., Hughes, M., Eshleman, S., Wittchen, H. U., and Kendler, K. S. (1994). Lifetime and 12-month prevalence of Dsm-Iii-R psychiatric-disorders in the United-States - results from the National-Comorbidity-Survey. Arch. Gen. Psychiatry 51, 8-19.

Krueger, R. F., Markon, K. E., Patrick, C. J., Benning, S. D., and Kramer, M. D. (2007). Linking antisocial behavior, substance use, and personality: an integrative quantitative model of the adult externalizing spectrum. $J$. Abnorm. Psychol. 116, 645-666.

Lind, P. A., Macgregor, S., Vink, J. M., Pergadia, M. L., Hansell, N. K., De Moor, M. H. M., Smit, A. B., Hottenga, J. J., Richter, M. M., Heath, A. C., Martin, N. G., Willemsen, G., de Geus, E. J. C., Vogelzangs, N., Penninx, B. W., Whitfield, J. B. Montgomery, G. W., Boomsma, D. I., and Madden, P. A. F. (2010).
A genomewide association study of nicotine and alcohol dependence in Australian and Dutch populations. Twin Res. Hum. Genet. 13, 10-29.

Littlefield, A. K., Agrawal, A., Ellingson, J. M., Kristjansson, S., Madden, P. A., Bucholz, K. K., Slutske, W. S., Heath, A. C., and Sher, K. J. (2011). Does variance in drinking motives explain the genetic overlap between personality and alcohol use disorder symptoms? A twin study of young women. Alcohol. Clin. Exp. Res. 35, 1-9.

Lynam, D. R., Leukefeld, C., and Clayton, R. R. (2003). The contribution of personality to the overlap between antisocial behavior and substance use/misuse. Aggress. Behav. 29, 316-331.

Mustanski, B. S., Viken, R. J., Kaprio, J., and Rose, R. J. (2003). Genetic influences on the association between personality risk factors and alcohol use and abuse. J. Abnorm. Psychol. $112,282-289$

Muthén, L. K., and Muthén, B. O. (2007). Mplus User's Guide, 5th Edn. Los Angeles, CA: Muthén \& Muthén.

Neale, M. C., Boker, S. M., Xie, G., and Maes, H. H. (2006). Mx: Statistical Modeling, 7 Edn. Richmond, VA: Department of Psychiatry, Virginia Commonwealth University.

Neale, M. C., and Cardon, L. R. (1992). Methodology for Genetic Studies of Twins and Families. Dordrecht: Kluwer Academic Publishers.

Nutt, D. J., King, L. A., and Phillips, L. D. (2010). Drug harms in the UK: a multicriteria decision analysis. Lancet 376, 1558-1565.

Pilia, G., Chen, W. M., Scuteri, A., Orru, M., Albai, G., Dei, M., Lai, S., Usala, G., Lai, M., Loi, P., Mameli, C., Vacca, L., Deiana, M., Olla, N., Masala, M., Cao, A., Najjar, S. S., Terracciano, A., Nedorezov, T., Sharov, A., Zonderman, A. B., Abecasis, G. R., Costa, P., Lakatta, E., and Schlessinger, D. (2006). Heritability of cardiovascular and personality traits in 6,148 sardinians. PLoS Genet. 2, e132. doi:10.1371/journal.pgen.0020132

Plomin, R., DeFries, J. C., Mcclearn, G. E., and McGuffin, P. (2001). Behavioral Genetics, 4th Edn. New York: Worth Publishers.

Prescott, C. A., and Kendler, K. S. (1999). Genetic and environmental contributions to alcohol abuse and dependence in a population-based sample of male twins. Am. J. Psychiatry 156, 34-40.

Rebollo, I., De Moor, M. H. M., Dolan, C. V., and Boomsma, D. I. (2006). Phenotypic factor analysis of family data: correction of the bias due to dependency. Twin Res. Hum. Genet. 9, 367-376 
Rehm, J., Baliunas, D., Borges, G. L. G., Graham, K., Irving, H., Kehoe, T., Parry, C. D., Patra, J., Popova, S., Poznyak, V., Roerecke, M., Room, R., Samokhvalov, A. V., and Taylor, B. (2010). The relation between different dimensions of alcohol consumption and burden of disease: an overview. Addiction 105, 817-843.

Rehm, J., Mathers, C., Popova, S., Thavorncharoensap, M., Teerawattananon, Y., and Patra, J. (2009). Alcohol and Global Health 1 Global burden of disease and injury and economic cost attributable to alcohol use and alcohol-use disorders. Lancet 373, 2223-2233.

Rehm, J., Room, R., Van den Brink, W., and Jacobi, F. (2005). Alcohol use disorders in EU countries and Norway: an overview of the epidemiology. Eur. Neuropsychopharmacol. 15, 377-388.

Reinert, D. F., and Allen, J. P. (2007). The alcohol use disorders identification test: an update of research findings. Alcohol. Clin. Exp. Res. 31, 185-199.

Rodgers, B., Korten, A. E., Jorm, A. F., Jacomb, P. A., Christensen, H., and Henderson, A. S. (2000). Non-linear relationships in associations of depression and anxiety with alcohol use. Psychol. Med. 30, 421-432.

Ruiz, M. A., Pincus, A. L., and Schinka, J. A. (2008). Externalizing pathology and the five-factor model: a metaanalysis of personality traits associated with antisocial personality disorder, substance use disorder, and their co-occurrence. J. Pers. Disord. $22,365-388$.

Sartor, C. E., Lynskey, M. T., Bucholz, K. K., Madden, P. A. F., Martin, N. G., and Heath, A. C. (2009). Timing of first alcohol use and alcohol dependence: evidence of common genetic influences. Addiction 104, 1512-1518.

Saunders, J. B., Aasland, O. G., Babor, T. F., de, l. F. Jr., and Grant, M. (1993). Development of the alcohol use disorders identification test (AUDIT): WHO collaborative project on early detection of persons with harmful alcohol consumption - II. Addiction $88,791-804$
Schermelleh-Engel, K., and Moosbrugger, H. (2003). Evaluating the fit of structural equation models: tests of significance and descriptive goodness-of-fit measures. Methods Psychol. Res. Online 8, 23-74.

Schumann, G., Coin, L. J., Lourdusamy, A., Charoen, P., Berger, K. H., Stacey, D., Desrivieres, S., Aliev, F. A., Khan, A. A., Amin, N., Aulchenko, Y. S., Bakalkin, G., Bakker, S. J., Balkau, B., Beulens, J. W., Bilbao, A., de Boer, R. A., Beury, D., Bots, M. L., Breetvelt, E. J., Cauchi, S., Cavalcanti-Proenca, C., Chambers, J. C., Clarke, T. K., Dahmen, N., de Geus, E. J., Dick, D., Ducci, F., Easton, A., Edenberg, H. J., Esko, T., Fernandez-Medarde, A., Foroud, T., Freimer, N. B., Girault, J. A., Grobbee, D. E., Guarrera, S., Gudbjartsson, D. F., Hartikainen, A. L., Heath, A. C., Hesselbrock, V., Hofman, A., Hottenga, J. J., Isohanni, M. K., Kaprio, J., Khaw, K. T., Kuehnel, B., Laitinen, J., Lobbens, S., Luan, J., Mangino, M., Maroteaux, M., Matullo, G., McCarthy, M. I., Mueller, C., Navis, G., Numans, M. E., Nunez, A., Nyholt, D. R., Onland-Moret, C. N., Oostra, B. A., O’Reilly, P. F., Palkovits, M., Penninx, B. W., Polidoro, S., Pouta, A., Prokopenko, I., Ricceri, F., Santos, E., Smit, J. H., Soranzo, N., Song, K., Sovio, U., Stumvoll, M., Surakk, I., Thorgeirsson, T. E., Thorsteinsdottir, U., Troakes, C., Tyrfingsson, T., Tonjes, A., Uiterwaal, C. S., Uitterlinden, A. G., van der, H. P., van der Schouw, Y. T., Staehlin, O., Vogelzangs, N., Vollenweider, P., Waeber, G., Wareham, N. J., Waterworth, D. M., Whitfield, J. B., Wichmann, E. H., Willemsen, G., Witteman, J. C., Yuan, X., Zhai, G., Zhao, J. H., Zhang, W., Martin, N. G., Metspalu, A., Doering, A., Scott, J., Spector, T. D., Loos, R. J., Boomsma, D. I., Mooser, V., Peltonen, L., Stefansson, K., van Duijn, C. M., Vineis, P., Sommer, W. H., Kooner, J. S., Spanagel, R., Heberlein, U. A., Jarvelin, M. R., and Elliott, P. (2011). Genome-wide association and genetic functional studies identify autism susceptibility candidate 2 gene (AUTS2) in the regulation of alcohol consumption.
Proc. Natl. Acad. Sci. U.S.A. 108, 7119-7124.

Sher, K. J., Grekin, E. R., and Williams, N. A. (2005). The development of alcohol use disorders. Annu. Rev. Clin. Psychol. 1, 493-523.

Shifman, S., Bhomra, A., Smiley, S., Wray, N. R., James, M. R., Martin, N. G., Hettema, J. M., An, S. S., Neale, M. C., Van den Oord, E. J. C. G., Kendler, K. S., Chen, X., Boomsma, D. I., Middeldorp, C. M., Hottenga, J. J., Slagboom, P. E., and Flint, J. (2008). A whole genome association study of neuroticism using DNA pooling. Mol. Psychiatry 13, 302-312.

Slutske, W. S., Heath, A. C., Madden, P. A. F., Bucholz, K. K., Statham, D. J., and Martin, N. G. (2002). Personality and the genetic risk for alcohol dependence. J. Abnorm. Psychol. 111, 124-133.

Steiger, J. H. (1990). Structural model evaluation and modification - an interval estimation approach. Multivariate Behav. Res. 25, 173-180.

Swendsen, J., Conway, K. P., Degenhardt, L., Glantz, M., Jin, R., Merikangas, K. R., Sampson, N., and Kessler, R. C. (2010). Mental disorders as risk factors for substance use, abuse and dependence: results from the 10-year follow-up of the National Comorbidity Survey. Addiction 105, 1117-1128.

Terracciano, A., Sanna, S., Uda, M. Deiana, B., Usala, G., Busonero, F., Maschio, A., Scally, M., Patriciu, N., Chen, W.-M., Distel, M. A., Slagboom, E. P., Boomsma, D. I., Villafuerte, S., Sliwerska, E., Burmeister, M., Amin, N., Janssens, A. C. J. W., van Duijn, C. M., Schlessinger, D., Abecasis, G. R., and Costa, P. T. (2010). Genome-wide association scan for five major dimensions of personality. Mol. Psychiatry 15, 647-656.

van Beek, J. H. D. A., Kendler, K. S., De Moor, M. H. M., Geels, L. M., Bartels, M., Vink, J. M., van den Berg, S. M., Willemsen, G., and Boomsma, D. I. (2011). Stable genetic effects on symptoms of alcohol abuse and dependence from adolescence into early adulthood. Behav. Genet. PMID: 21818662. [Epub ahead of print].

van den Oord, E. J., Kuo, P. H., Hartmann, A. M., Webb, B. T., Moller, H. J., Hettema, J. M., Giegling, I., Bukszar, J., and Rujescu, D. (2008). Genomewide association analysis followed by a replication study implicates a novel candidate gene for neuroticism. Arch. Gen. Psychiatry 65, 1062-1071.

Whitfield, J. B., Zhu, G., Madden, P. A., Neale, M. C., Heath, A. C., and Martin, N. G. (2004). The genetics of alcohol intake and of alcohol dependence. Alcohol. Clin. Exp. Res. 28, 1153-1160.

Yu, C. Y. (2002). Evaluating Cutoff Criteria of Model Fit Indices for Latent Variable Models with Binary and Continuous Outcomes. Dissertation from University of California, Los Angeles.

Conflict of Interest Statement: The authors declare that the research was conducted in the absence of any commercial or financial relationships that could be construed as a potential conflict of interest.

Received: 01 August 2011; accepted: 16 October 2011; published online: 02 November 2011.

Citation: de Moor MHM, Vink JM, van Beek JHDA, Geels LM, Bartels $M$, de Geus EJC, Willemsen $G$ and Boomsma DI (2011) Heritability of problem drinking and the genetic overlap with personality in a general population sample. Front. Gene. 2:76. doi: 10.3389/fgene.2011.00076

This article was submitted to Frontiers in Behavioral and Psychiatric Genetics, a specialty of Frontiers in Genetics. Copyright (c) 2011 de Moor, Vink, van Beek, Geels, Bartels, de Geus, Willemsen and Boomsma. This is an open-access article subject to a non-exclusive license between the authors and Frontiers Media $S A$, which permits use, distribution and reproduction in other forums, provided the original authors and source are credited and other Frontiers conditions are complied with. 